\title{
Use of ECT in patients with an intellectual disability: review
}

\author{
Jessica Collins, ${ }^{1}$ Neel Halder, ${ }^{2,3}$ Nasim Chaudhry ${ }^{3,4}$
}

The Psychiatrist (2012), 36, 55-60, doi: 10.1192/pb.bp.110.033811

${ }^{1}$ Salford Royal NHS Foundation Trust: ${ }^{2}$ Alpha Hospital, Bury; ${ }^{3}$ University of Manchester; ${ }^{4}$ Greater Manchester West Mental Health NHS Foundation Trust

Correspondence to Neel Halde (neel.halder@alphahospital.co.uk)

First received 9 Dec 2010, final revision 20 Jul 2011, accepted 14 Sep 2011
Aims and method The literature on the use of electroconvulsive therapy (ECT) in patients with an intellectual disability is scarce, despite a higher prevalence of psychiatric disorders than in the general adult population. We carried out a review of articles published before March 2010. All age ranges, severity of disability and diagnoses were included.

Results We found 72 case reports, a retrospective chart review study and other reviews, but no controlled studies. Most patients (79\%) showed a positive outcome following ECT. Complications were seen only in $13 \%$ and there were no reports of cognitive decline. Many patients relapsed following ECT (32\%) and the majority were maintained with medication at follow-up (71\%).

Clinical implications Electroconvulsive therapy is a valuable treatment for this patient group and should be considered earlier as opposed to as a last resort. Obstacles to its use include diagnostic difficulties, ethical and legal issues, a lack of objective measurements and uncertainty about its safety in this population.

Declaration of interest None.
It has been suggested that the prevalence of psychiatric disorders is much higher in individuals with an intellectual disability than in the general population. ${ }^{1-3}$ A wide range of psychiatric treatments for this patient group are being used successfully in practice. However, electroconvulsive therapy (ECT), a treatment that has been proved beneficial in certain conditions in the general adult population, ${ }^{1,4,5}$ appears to be underused in patients with an intellectual disability. ${ }^{1}$ At the Royal College of Psychiatrists Faculty of the Psychiatry of Learning Disability's annual conference in 2010, we discussed this with some psychiatrists in this field who were unaware that ECT has ever been used in this group of patients.

Moreover, despite thorough guidance on the recommended use of ECT, the National Institute for Health and Clinical Excellence has not made any recommendations on its use in patients with an intellectual disability, ${ }^{4}$ and the evidence of its efficacy in the literature is sparse. In the Royal College of Psychiatrists The ECT Handbook, the use of ECT in people with intellectual disabilities was thus reviewed: ${ }^{5,6}$

'It would be good practice to use ECT only in carefully selected cases, usually where the psychiatric illness has proved refractory to medical treatment or where there are intolerable adverse effects of medication, or where the clinical condition of the sufferer has severely deteriorated... There are no absolute contraindications to the use of ECT in patients with a learning disability' (p. 65-6).

Owing to the apparent lack of guidelines and clinicians' uncertainty over whether ECT is used in this population, we decided to carry out a literature review to assess the current practice. We discovered that the most recent review on this subject was conducted over a decade ago by van Waarde et $a l .{ }^{7}$ We aimed to further this work by reviewing more recent published literature, along with evidence already previously reviewed, and answer the following questions.

1 To what extent has, or is, ECT being carried out in people with an intellectual disability?

2 Which conditions has ECT been used to treat in this population?

3 How successful has ECT treatment been for these patients and has it resulted in any complications or side-effects?

4 What factors influenced the decision to prescribe ECT for these patients?

\section{Method}

An online literature search for national and international journal articles published before March 2010 was conducted using the following databases: PubMed, MEDLINE, PsycINFO, AMED, ProQuest British Nursing Index, CINAHL, Embase, Health Business ${ }^{\mathrm{TM}}$ Elite, NHS Health Evidence Information Consortium. The search terms were: 'ECT and', 'electroconvulsive therapy and', 'electric shock therapy and', 'learning disabilities', 'intellectual disability', 'mental retardation', 'mental deficiency', 'developmental disability', 'learning difficulty', 'developmental difficulty’. 
Table 1 Psychiatric diagnoses and levels of intellectual disability in the reviewed studies

\begin{tabular}{lcccccc} 
& \multicolumn{5}{c}{ Severity, $n(\%)$} \\
\cline { 3 - 7 } Diagnosis & Cases, $n(\%)$ & Mild & Moderate & Severe & Profound & Not stated \\
\hline Affective disorder & $42(58)$ & $21(50)$ & $12(29)$ & $1(2)$ & $1(2)$ & $7(17)$ \\
\hline Schizophrenia & $6(8)$ & $3(50)$ & $2(33)$ & $1(17)$ & - & - \\
\hline Schizoaffective disorder & $7(10)$ & $6(86)$ & $1(14)$ & - & - & - \\
\hline Behavioural disturbances & $4(6)$ & $1(25)$ & $2(50)$ & $1(25)$ & - & - \\
\hline Catatonia & $4(6)$ & $1(25)$ & $1(25)$ & - & - & $1(14)$ \\
\hline Mixed & $7(10)$ & $4(57)$ & $2(29)$ & - & - & - \\
\hline Other & $1(1)$ & - & $1(100)$ & - & - & - \\
\hline Not stated & $1(1)$ & $1(100)$ & - & - & - \\
\hline
\end{tabular}

The eligibility criteria included any study (from individual case reports to randomised controlled trials) that included adults and children of any age with any severity of intellectual disability, as identified by the ICD-10, ${ }^{8}$ undergoing treatment for any reason. A thorough check of references in the articles was also conducted to make sure that other sources had not been missed.

As there was only one reviewer, all reports were read and analysed in a standardised manner. The PRISMA guidelines were used to inform the methods and write-up at all stages of the study. ${ }^{9}$

\section{Results}

A total of 72 cases of ECT use in patients with an intellectual disability were found in the literature..$^{1-3,10-44}$ Many studies were case reports; others were case-series reviews or were part of other literature reviews. No prospective, case-controlled or randomised controlled studies were identified.

In the cases identified, ECT was used in both male and female patients between the ages of 14 and 69 . Out of the 72 cases, $51 \%(n=37)$ of individuals had mild intellectual disability, 29\% $(n=21)$ had moderate disability, $4 \%(n=3)$ severe and $2 \%(n=2)$ profound; in $12.5 \%(n=9)$ the severity of intellectual disability was not stated. We used the IQ levels as given in the ICD-10 to categorise the severity of intellectual disability. ${ }^{8}$

Indications for ECT were wide ranging (Table 1). Affective disorders were by far the most commonly diagnosed both in total (59\%) and in each level of severity of intellectual disability. Some patients had no documented diagnosis (10\%), but presented with varied/mixed symptoms.

The majority of patients had undergone several trials of multiple medications before ECT was prescribed. Only in 45 cases the exact medications that had been trialled prior to ECT were reported, but of these, an average number of 5 different medications were tried, including various antidepressants, antipsychotics, benzodiazepines, sedatives, anxiolytics and mood stabilisers. Four patients had been treated with ECT in the past and two had received behaviour therapy.

There was a wide range in the total number of ECT treatments received by patients and the course given did
Table 2 Range of treatments given within each category of intellectual disability

\begin{tabular}{lc} 
Level of intellectual disability & Average, $n$ (range) \\
\hline Mild & $8(1-18)$ \\
\hline Moderate & $9(3-21)$ \\
\hline Severe & $7(1-12)$ \\
\hline Profound & $8(6-10)$ \\
\hline
\end{tabular}

not seem to correlate to the severity of intellectual disability (Table 2). This may partly be due to the small numbers of patients with severe and profound intellectual disability in the studies. Overall, bilateral electrode placement was far more commonly used than unilateral placement.

The therapy resulted in a positive outcome in the majority of cases (79\%) and most patients in each level of severity of intellectual disability had a positive outcome (Table 3). Only in seven cases (10\%) was a negative outcome or no improvement at all reported; 20 patients (28\%) required continuation/maintenance ECT and 51 (71\%) required medication during the follow-up. One patient also received occupational and art therapy after she completed her ECT treatment.

Despite the large number of apparent successes, there were also a large number of relapses: 23 patients (32\%) experienced at least one relapse following the reported course of ECT and 16 of those patients required further ECT treatments.

\section{Complications}

Complications following ECT arose in nine cases (12\%) and included: transient mild memory impairment, ${ }^{12}$ drowsiness for $24 \mathrm{~h},{ }^{35}$ delirium in a man with autism receiving ECT for severe depression, catatonia and self-injury, ${ }^{40}$ and 'flat facial expression' after four treatments that resolved spontaneously 3 weeks later. ${ }^{35}$ Several studies reported an increase in agitation, both in the postictal state ${ }^{23}$ and following several treatments. ${ }^{35}$ One patient, who had underlying chronic obstructive pulmonary disease, became agitated and hypoxic, requiring nebulisations of albuterol and beclomethasone. ${ }^{2}$ Seizures were noted in two cases, one of a person having two fits (not described) following an ECT 
Table 3 Outcome of electroconvulsive therapy in the sample

\begin{tabular}{|c|c|c|c|c|c|c|}
\hline \multirow[b]{2}{*}{ Outcome } & \multirow[b]{2}{*}{ Cases, n (\%) } & \multicolumn{5}{|c|}{ Severity, $n(\%)$} \\
\hline & & Mild & Moderate & Severe & Profound & Not stated \\
\hline Positive (full improvement) & $57(79)$ & $28(49)$ & $18(32)$ & $2(4)$ & $2(4)$ & $7(12)$ \\
\hline Negative (no improvement) & $7(10)$ & $5(71)$ & $2(29)$ & - & - & - \\
\hline $\begin{array}{l}\text { Mixed (improvement of some } \\
\text { symptoms but not others) }\end{array}$ & $5(7)$ & $2(40)$ & $1(20)$ & $1(20)$ & - & $1(20)$ \\
\hline Not stated & $3(4)$ & $2(67)$ & - & - & - & $1(33)$ \\
\hline
\end{tabular}

session, ${ }^{1}$ and another of a male with moderate intellectual disability who developed non-convulsive status epilepticus after his ninth ECT session for catatonic psychosis. ${ }^{26}$

\section{Objective measurements of outcome used}

Two retrospective chart review studies that objectively measured the outcome of ECT using standardised rating scales were also found in the literature. Out of the total 72 cases, 10 had been reviewed retrospectively by Friedlander \& Solomons, ${ }^{35}$ who assessed the outcome of ECT using the Clinical Global Impressions (CGI) scale. Out of the 10 patients they reviewed, 7 had 'much improved or very much improved', indicated by a CGI score of either 1 or 2 , and this improvement was 'rapid and dramatic'. The remaining three patients had an 'equivocal response', indicated by a CGI score of 3 or 4 . None of the patients deteriorated during the course of treatment.

Similarly, Reinblatt et $a l^{45}$ reviewed 20 in-patients to assess symptoms and clinical improvement after ECT treatment, using the CGI scale and Aberrant Behaviour Checklist (ABC). This was then compared with patients' initial diagnoses to determine whether ECT may be more efficacious for certain diagnoses in this patient population. This study showed that most patients had a good response to ECT, but also concluded that ECT was most useful for 'mood disorders and psychotic disorders, after adequate pharmacological trials have failed'. Out of the five subscales of the $\mathrm{ABC}, \mathrm{ECT}$ was most effective in treating irritability and hyperactivity. The study found no side-effects and, although not formally tested for, signs of cognitive impairment or deterioration were not observed.

A further 3 cases (out of the 72) objectively measured the outcome of ECT using similar scales to the studies above. Puri et $a l^{15}$ used the Adaptive Behaviour Scale (ABS) in a male with mild intellectual disability treated for chronic relapsing depression. The patient showed improvement in all ten areas of the ABS and had fewer maladaptive behaviours. Gabriel ${ }^{29}$ used the Brief Psychiatric Rating Scale (BPRS) and the Global Assessment of Functioning scale (GAF) for a female patient with moderate intellectual disability treated for refractory psychosis. The patient's score on the BPRS decreased from 85 to 42 and her score on the GAF increased from 25 to 40 , indicating significant clinical improvement. Mackay \& Wilson $^{39}$ reported a dramatic improvement in the mental state of a female with mild intellectual disability after she received treatment for depression. This was measured using the Glasgow
Depression Scale for people with Learning Disability (GDS-LD).

\section{Discussion}

The results of this review show that ECT has been used effectively and with few serious side-effects for a wide range of psychiatric disorders in individuals with an intellectual disability. In particular, it has been used for those patients whose illness is treatment resistant and whose condition has severely deteriorated. There was no reported evidence of further cognitive decline in any of the case studies. Relapses following ECT treatment were noted, but this also often occurs in the general adult population. ${ }^{7}$ This suggests that ECT may be a particularly useful treatment for this patient group, especially when used as an adjunct to other treatments, and so could potentially be applied more frequently, particularly in challenging cases. Reid, ${ }^{46}$ who reviewed 21 patients with an intellectual disability and 'manic depressive psychosis', concluded that a combination of antidepressants and ECT was effective in most patients with mild and borderline disability.

Despite the positive nature of the results, we also found several reported obstacles to the use of ECT in patients with intellectual disabilities, which are summarised below.

\section{Diagnostic uncertainty}

Diagnostic problems are quoted frequently in the literature. In the survey by Cutajar \& Wilson ${ }^{1}$ of consultant opinions on the use of ECT in intellectual disability, difficulties with diagnosis was a frequently quoted reason as to why consultants believe ECT is underused in these patients. Sayal \& Bernard ${ }^{47}$ also quoted 'diagnostic overshadowing' as a problem in which 'the knowledge of the presence of a learning disability reduces the likelihood that emotional or behavioural disturbance is appropriately diagnosed'. This can result in delayed use of ECT. ${ }^{37}$

The impact of diagnostic difficulties in prescribing ECT to patients with an intellectual disability was first raised as an issue for discussion in $1996^{16}$ and was still being discussed in 2010. ${ }^{41}$ This highlights the need for further improvements in diagnostic acuity in this patient group.

\section{Consent and agreement among key groups}

Many individuals with intellectual disability lack the capacity to give informed consent, ${ }^{6}$ although, in keeping with the Mental Capacity Act 2005, every effort must be 
made before this conclusion is reached. ${ }^{48}$ Mackay \& Wilson $^{39}$ reported the case of a young female with mild intellectual disability who was able to give informed consent for ECT for major depression through the use of a communication tool provided by speech and language therapists, 'Talking Mats', which uses pictures to help patients understand treatments and their implications. ${ }^{39}$ It is possible that professionals from key groups who are involved in the care of these patients could be trained to use such tools to improve ways of gaining consent in the future.

Problems with obtaining informed consent are a recurring theme in the literature and clinicians seem to view this as a major stumbling block..$^{1,2,6,7,10,36,39,45}$ Cutajar \& Wilson $^{1}$ quoted 'obtaining informed consent' as a practical difficulty in ECT administration. Legal issues surrounding consent can be complex, and inevitably differ across the world and even in different areas in the UK. ${ }^{6,7}$ If a patient is incapacitated but complies, in most settings a 'best interests' meeting is held in which carers, professionals and practitioners involved in different aspects of the patient's care and support will discuss the best way to proceed. ${ }^{49}$ This is in concordance with the Mental Capacity Act 2005, which in Part 1.1 states that 'An act done, or decision made, under this Act for or on behalf of a person who lacks capacity must be done, or made, in his best interests.' The Act outlines the principles of 'best interests' in Part 1.4.

In general adult psychiatry, if ECT is deemed appropriate and the best treatment option for a patient who is unable to consent and unwilling to comply with treatment, Section 58A of the Mental Health Act 1983 (2007 amendment) can be applied to prescribe ECT and medication given as part of ECT. This principle applies in people with an intellectual disability as it does in the mainstream population.

Given the often negative perception of ECT as a treatment, the process of reaching a decision may be even more challenging if carers, relatives and support workers are not properly educated about its indications, procedure and effects. ${ }^{7,45}$ Consultant psychiatrists identified 'resistance by carers/staff' as a reason why ECT is underused in this population. ${ }^{1}$ It has also been described that in some countries patients have been undertreated with ECT due to lobbying by advocacy groups against continuing the treatment. $^{35}$ This shows that more work needs to be done to educate and allay fears in these key groups as well as in the wider population.

\section{Adverse cognitive effects}

One of the main fears of using ECT in patients with intellectual disability is that it will cause a further degree of cognitive decline or brain damage. ${ }^{7}$ Sayal \& Bernard ${ }^{47}$ stated that this could have been a reason as to why trainees in their study were less likely to agree to the use of ECT in a case vignette of a patient with an intellectual disability. Previous studies demonstrate that consultants gave 'irrational fear of worsening pre-existing organic damage' as a reason why ECT is underused in those patients. ${ }^{1}$

Although there is evidence to support cognitive sideeffects of ECT such as amnesia, there is no evidence in the ECT literature that it causes actual brain damage,,$^{2,50-52}$ and in all of the cases studied in this review, none reported any serious cognitive decline or adverse cognitive side-effects following ECT. Friendlander \& Solomons ${ }^{35}$ stated that 'this finding is not unexpected, as other at-risk populations, such as geriatric patients with dementia or adolescents with severe mental illness have not been shown to be at increased risk of cognitive side effects.' Similarly, van Waarde et $a l^{7}$ noted that ECT has been used safely in patients who have central nervous system disorders. However, since there have been no controlled studies that look particularly at the effects of ECT in patients with an intellectual disability, it cannot be said that ECT is completely safe in this population, and because there is no firm guidance on how it should be used in these patients, it is understandable why most clinicians are reluctant to try it.

\section{Pharmacology}

The majority of patients in this review who eventually received ECT had first been tried on multiple psychotropic medications, whereas it has been reported that individuals with intellectual disabilities are more biologically and cognitively sensitive to medications and are also at a greater risk of adverse side-effects. ${ }^{3,7,41,42}$ This is thought to be due to structural brain differences and coexistence of other somatic disorders. ${ }^{7}$ If patients with intellectual disability are likely to suffer more because of these medications and their inability to report somatic side-effects, it may be that ECT would benefit them by reducing the need for multiple medications. ${ }^{3}$ Therefore, in specific patients, ECT may actually be the more conservative treatment option. ${ }^{7}$ Reducing the number of unnecessary medications would also inevitably result in cost savings; still, such savings would have to be balanced against the cost of prescribing ECT. As currently there are no studies that compare the efficacy, safety and cost-efficiency of ECT with that of medications in patients with an intellectual disability, ${ }^{7}$ one can only speculate on this point.

\section{Ethical considerations}

Because ECT was mainly used as a last resort, the condition of several patients before ECT treatment deteriorated to the extent that it was deemed life threatening. Many patients experienced multiple somatic symptoms such as food refusal, profound weight loss, urinary retention, incontinence and motor disturbances, and others displayed dangerous self-injurious behaviours, suicidality, aggression and violence towards carers, which resulted in them being kept in restraints for a large part of the day. ${ }^{41}$ On the other hand, once ECT was commenced, many patients showed a dramatic and rapid improvement. We argue that it is not ethical to leave patients in such a state when there is an alternative treatment available that could be very successful. We agree with other authors who feel that ECT should be considered more promptly in severe cases rather than being seen as a treatment of last resort. ${ }^{36,40}$ Prompt treatment with ECT could also have implications for key individuals involved in the day-to-day care of these patients, as it could bring in cost savings through a reduction in levels of staffing and supervision required. 
In their review of clinical and ethical issues, Little et $a l^{36}$ put forward the argument that clinicians can use ethical justification to help them with the decision to prescribe ECT. They cite the literature describing the ethical justification for ECT in general psychiatry and propose that further ethical support be drawn from utilitarian-based and duty-based reasoning. ${ }^{36}$ They also state that in the absence of guidance from the literature, the potential for causing adverse cognitive effects through the use of ECT can be justified under the rule of double effect. ${ }^{36}$

The complex ethical arguments embedded in the issue of ECT use in people with an intellectual disability could fill a paper of their own, and they are unfortunately outside the scope of this review. Until further studies are conducted, clinicians will have to rely on other forms of support/ guidance when considering this treatment option in patients with an intellectual disability.

The need for controlled and valid research into this field has been highlighted several times in this review; yet controlled studies with people with an intellectual disability are often complicated to conduct both methodologically and ethically. ${ }^{53}$ Issues faced by researchers involve several we have already mentioned, such as problems with gaining informed consent, the lack of reliable measuring scales and attitudes of both professionals and lay groups. Other problems have also been reported, such as the need to obtain formal approval from agencies or service providers to gain access to potential participants, the time-consuming nature of designing and conducting studies in this population, and problems with dissemination after research is complete. ${ }^{53,54}$ There is also much discussion in the literature about involving individuals with intellectual disability in the research process, giving rise to lengthy debates about participatory and emancipatory research designs. ${ }^{55}$ Such deliberations are outside the scope of this paper, yet they are pertinent to any research in this population.

In addition to the issues discussed, all researchers will have to gain ethical approval for their study, which can be a complex and lengthy process for any type of research, ${ }^{56}$ but is even more so for a cohort with an intellectual disability, as such individuals are viewed as being vulnerable. ${ }^{57}$ This may appear as a further barrier to potential researchers.

Despite these problems, it is evident in the literature that randomised controlled trials conducted in intellectual disability psychiatry are on the increase, ${ }^{58}$ which is certainly a step in the right direction.

\section{Study limitations}

As we identified no controlled studies and this review is based mainly on case reports, in which there may have been elements of selective reporting, it is difficult to draw firm conclusions about the use of ECT in patients with an intellectual disability. Moreover, the sample is relatively small and there is a definite skew in the severity of intellectual disability represented, with the majority of case reports being of patients with mild and moderate disability.

All the reports were identified and reviewed in a standardised manner by one reviewer. Still, there remains the possibility of publication bias favouring positive results. $^{7,17}$ This may affect the cumulative evidence and means that the results should be interpreted with caution. Only a handful of studies measured outcome and effects on cognitive function in an objective, standardised manner, using validated rating scales. ${ }^{12,15,18,29,39}$ Most authors used subjective clinical observation and judgement to determine outcome, which makes it difficult to compare cases and interpret the outcomes objectively.

Finally, despite carrying out a thorough literature search, only English-language journals were searched.

\section{About the authors}

Jessica Collins is an FY doctor at Salford Royal NHS Foundation Trust, Neel Halder is a consultant psychiatrist and honorary senior lecturer at the University of Manchester, and Nasim Chaudhry is a consultant psychiatrist in learning disability at Greater Manchester West Mental Health NHS Trust and honorary lecturer at Manchester University.

\section{References}

1 Cutajar P, Wilson D. The use of ECT in intellectual disability. J Intellect Disabil Res 1999; 43: 421-7.

2 Thuppal M, Fink M. Electroconvulsive therapy and mental retardation. J ECT 1999; 15: 140-9.

3 Aziz M, Maixner DF, DeQuardo J, Aldridge A, Tandon R. ECT and mental retardation: a review and case reports. J ECT 2001; 17: 149-52.

4 National Institute for Health and Clinical Excellence. Guidance on the Use of Electroconvulsive Therapy (Technology Appraisal 59). NICE, 2010.

5 Scott AIF. The ECT Handbook (Second Edition). Gaskell, 2005.

6 Muir WJ. The use of ECT in people with learning disability. In The ECT Handbook (Second Edition) (ed. AIF Scott): 57-67. Gaskell, 2005.

7 van Waarde JA, Stolker JJ, van der Mast RC. ECT in mental retardation: a review. J ECT 2001; 17: 236-43.

8 World Health Organization. The ICD-10 Classification of Mental and Behavioural Disorders. WHO, 1992: 369-70.

9 Moher D, Liberati A, Tetzlaff J, Altman DG. Preferred reporting items for systematic reviews and meta-analyses: the PRISMA statement. PLoS Med 2009; 6: e1000097. doi:10.1371/journal.pmed1000097.

10 Bates WJ, Smeltzer DJ. Electroconvulsive treatment of psychotic selfinjurious behaviour in a patient with severe mental retardation. Am J Psychiatry 1982; 39: 1355-6.

11 Goldstein MZ, Jensvold MF. ECT treatment of an elderly mentally retarded man. Psychosomatics 1989; 30: 104-6.

12 Lazarus A, Jaffe RL, Dubin WR. Electroconvulsive therapy and major depression in Down's syndrome. J Clin Psychiatry 1990; 51: 422-5.

13 Merrill RD. ECT for a patient with profound mental retardation (letter). Am J Psychiatry 1990; 147: 256-7.

14 Karvounis S, Holt G, Hodgkiss A. Out-patient ECT for depression in a man with moderate learning disability (letter). Br J Psychiatry 1992; 161: 426-7.

15 Puri BK, Langa A, Coleman RM, Singh I. The clinical efficacy of maintenance electroconvulsive therapy in a patient with a mild mental handicap. Br J Psychiatry 1992; 161: 707-9.

16 Bebchuk JM, Barnhill J, Dawkins K. ECT and mental retardation (letter). Am J Psychiatry 1996; 153: 1231.

17 Reudrich SL, Alamir S. Electroconvulsive therapy for persons with developmental disabilities: review, case report and recommendations. Mental Health Asp Dev Disabil 1999; 2: 83-91.

18 Chanpattana W. Maintenance ECT in mentally retarded, treatmentresistant schizophrenic patients. J ECT 1999; 15: 150-3.

19 Warren AC, Holroyd S, Folstein MF. Major depression in Down's syndrome. Br J Psychiatry 1989; 155: 202-5. 
20 Guze BH, Weinman B, Diamond RP. Use of ECT to treat bipolar depression in a mental retardate with cerebral palsy. Convuls Ther 1987; 3: $60-4$

21 Kearns A. Cotard's syndrome in a mentally handicapped man. Br J Psychiatry 1987; 150: 112-4

22 Payne R. The psychotic subnormal. J Ment Subnorm 1968; 14: 25-34

23 Slack T, Stoudemire A. Reinstitution of neuroleptic treatment with molindone in a patient with a history of neuroleptic malignant syndrome. Gen Hosp Psychiatry 1989; 11: 365-7.

24 Day KA. Depression in moderately and mildly mentally handicapped people. In Depression in Mentally Retarded Children and Adults (eds A Doen, FJ Menolascino): 129-54. Logon Publications, 1990.

25 Renshaw PF, Stern TA, Welch C, Schouten R, Kolodny EH Electroconvulsive therapy treatment of depression in a patient with adult GM2 gangliosodosis. Ann Neurol 1992; 31: 342-4.

26 Jyoti Rao KM, Gangadhar BN, Janakiramaiah N. Nonconvulsive status epilepticus after the ninth electroconvulsive therapy (letter). Convuls Ther 1993; 9: 128-9.

27 Jancar J, Gunaratne IJ. Dysthymia and mental handicap. Br J Psychiatry 1994; 164: 691-3.

28 Snowdon J, Meehan T, Halpin R. Continuous screaming controlled by electroconvulsive therapy: a case study. Int J Geriatr Psychiatry 1994; 9 929-32.

29 Gabriel A. ECT continuation and maintenance in a patient with psychosis and mental disability (letter). Can J Psychiatry 1998; 43: 305-6.

30 Cutajar P, Wilson DN, Mukherjee T. ECT used in depression following childbirth in a woman with learning disabilities. Br J Learn Dis 1998; 26: $115-7$.

31 Fink M. Depressive mood disorders. In Electroshock: Restoring the Mind. Oxford University Press, 1999: 31-51.

32 Fink M. Movement disorders. In Electroshock: Restoring the Mind. Oxford University Press, 1999: 66-79.

33 Gothelf D, Frisch A, Munitz $H$, Rockah $R$, Laufer $N$, Mozes $T$, et al. Clinical characteristics of schizophrenia associated with velo-cardiofacial syndrome. Schizophr Res 1999; 35: 105-12.

34 van Waarde JA, Stolker JJ, Soleman ACA. Electroconvulsive therapy in people with mental retardation [in Dutch]. Tijdschr Psychiatr 2000; 42: 811-24.

35 Friedlander RI, Solomons K. ECT: use in individuals with mental retardation. J ECT 2002; 18: 38-42.

36 Little JD, McFarlane J, Ducharme HM. ECT use delayed in the presence of comorbid mental retardation: a review of clinical and ethical issues. J ECT 2002; 18: 218-22.

37 Kessler RJ. Electroconvulsive therapy for affective disorders in persons with mental retardation. Psychiatr Quart 2004; 75: 99-104.

38 Myers CL, Dinwiddie SH. ECT in a man with FG syndrome. J ECT 2007; 23: 33-5.

39 Mackay F, Wilson C. Successful multi-disciplinary and multi-treatment working for a person with learning disability who experienced major depressive disorder. Learn Dis Rev 2007; 12: 39-47.
40 Ligas A, Petrides G, Istafanous R, Kellner CH. Successful electroconvulsive therapy in a patient with intellectual disability and bipolar disorder with catatonic features misdiagnosed as encephalopathy. J ECT 2009; 25: 202-4.

41 Wachtel LE, Griffin M, Reti IM. Electroconvulsive therapy in a man with autism experiencing severe depression, catatonia and self-injury. J ECT 2010; 26: 70-3.

42 Wachtel LE, Hermida A, Dhossche DM. Maintenance electroconvulsive therapy in autistic catatonia: a case series review. Prog Neuropsychopharmacol Biol Psychiatry 2010; 34: 581-7.

43 Zaw FKM, Bates GDL, Murali V, Bentham P. Catatonia, autism and ECT. Dev Med Child Neurol 1999; 41: 843-5.

44 Everman DB, Stoudemire A. Bipolar disorder associated with Klinefelter's Syndrome and other chromosomal abnormalities. Psychosomatics 1994; 35: 35-40.

45 Reinblatt SP, Rifkin A, Freeman J. The efficacy of ECT in adults with mental retardation experiencing psychiatric disorders. J ECT 2004; 20: 208-12.

46 Reid $\mathrm{AH}$. Psychoses in adult mental defectives: I. Manic depressive psychosis. Br J Psychiatry 1972; 120: 205-12.

47 Sayal K, Bernard S. Trainees' assessment and management of mental illness in adults with mild learning disabilities. Psychiatr Bull 1998; 22: $571-2$.

48 Barnes R, Dyer JAT, McClelland RJ, Scott AIF. The law and consent to treatment. In The ECT Handbook (Second Edition) (ed. AIF Scott). Gaskell, 2005.

49 Department of Health. Seeking Consent: Working with People with Learning Disabilities. Department of Health, 2001 (http:// www.dh.gov.uk/prod_consum_dh/groups/dh_digitalassets/@dh/@en/ documents/digitalasset/dh_4067019.pdf).

50 Weiner RD. Does electroconvulsive therapy cause brain damage? Beha Brain Sci 1984; 7: 1-53.

51 Devanand DP, Dwork AJ, Hutchinson ER, Bolwig TG, Sackeim HA. Does ECT alter brain structure? Am J Psychiatry 1994; 151: 957-70.

52 Puri BK, Oatridge A, Saeed N, Ging JE, McKee HM, Lekh SK, et al. Does electroconvulsive therapy lead to changes in cerebral structure? $\mathrm{Br} J$ Psychiatry 1998; 173: 267.

53 Stalker K. Some ethical and methodological issues in research with people with learning difficulties. Disab Soc 1998; 13: 5-19.

54 Rodgers J. Trying to get it right: undertaking research involving people with learning difficulties. Disab Soc 1999; 14: 421-33.

55 Gilbert T. Involving people with learning disabilities in research: issues and possibilities. Health Soc Care Community 2004; 12: 298-308.

56 Smajdor A, Sydes MR, Gelling L, Wilkinson M. Applying for ethical approval for research in the United Kingdom. BMJ 2009; 339: 4013.

57 Hays SJ, Murphy G, Sinclair N. Gaining ethical approval for research into sensitive topics: 'two strikes and you're out?' Br J Learn Dis 2003; 31: $181-9$.

58 Hassiotis A. Research in mental health learning disabilities: present challenges and future drivers. Psychiatry 2009; 8: 457-60. 